\section{International Scientific Journal Theoretical \& Applied Science}

\author{
p-ISSN: 2308-4944 (print) e-ISSN: 2409-0085 (online) \\ Year: $2015 \quad$ Issue: $11 \quad$ Volume: 31 \\ Published: $30.11 .2015 \quad$ http://T-Science.org
}

Svetlana Iliinichna Shamarova

Associate Professor,

$\mathrm{Ph}$. D. in Philology,

The Ufa Centre of foreign languages training,

Russia

shamarova@list.ru

SECTION 18. Culturology.

\title{
THE WOLF AS ONE OF «THE BEASTS OF BATTLE» IN MYTHOLOGY AND FOLKLORE
}

Abstract: The article presents the hypothesis regarding the interpretation of contradictory and ambiguous attitude of peoples worldwide towards a wolf one of the beasts of battle on the basis of pagan and christian mythology and folklore as to a deity or a semideity, which was retained not only in the language, but also in particular objects and phenomena.

Key words: mythology, folklore, the wolf, battle.

Language: Russian

Citation: Shamarova SI (2015) THE WOLF AS ONE OF «THE BEASTS OF BATTLE» IN MYTHOLOGY AND FOLKLORE. ISJ Theoretical \& Applied Science 11 (31): 180-184.

Soi: http://s-o-i.org/1.1/TAS-11-31-29 Doi: crossef http://dx.doi.org/10.15863/TAS.2015.11.31.29

\section{ВОЛК КАК ОДИН ИЗ «ХИЩНИКОВ БИТВЫ» В МИФОЛОГИИ И ФОЛЬКЛОРЕ}

Аннотация: В статье представлена гипотеза относительно толкования противоречивого и неоднозначного отношения народов мира к волку, как одному из зверей боя на основе языческой и христианской мифологии и фольклору как к божеству или полу-божеству, которое сохраняется не только в языке, но и в частности объектов и явлений.

Ключевые слова: мифология, фольклор, волк, битва.

Большой интерес к волку проявлялся не только в глубокой древности, но и в сравнительно недавнее время. Например, название Лувра в Париже связано с формой самого строения, подобного логову волка, по замыслу автора - строителя Филиппа Аугустуса $[1$, c. 1$]$. В скандинавской и японской мифологии волки изображаются богоподобными существами. В Японии фермеры поклонялись волкам в раках и оставляли жертвоприношения (еду) рядом с их берлогами, умоляя их защищать свои посевы от диких кабанов и оленей. В скандинавской мифологии (поэтической “Эдде”) фигурируют три злых волка - хтонические существа: великан Фенрир (старший сын Локи брата верховного бога Одина) и его дети, Сколл и Хати. Фенрир пожирает Одина, а его дети солнце и луну в мифе о Рагнареке (“Судьба богов”, “Гибель богов”). «Рагнарек - это полное уничтожение мира силами зла» [2, с.164], к которым и относится волк Фенрир. С другой стороны, волки Гери (Жадный) и Фреки (Прожорливый) были преданными и добрыми питомцами бога Одина. В мифологии турков, монголов и айну волки считались родоначальниками, предками их народа, а в мифологии коренных американских жителей танаина волки когда-то были людьми и к ним относились как к братьям. В чечено-ингушской мифологии волки всегда предстают в положительном свете как любящая "Волчица мать”, в то время как в Финляндии волков всегда боятся и ненавидят. Волк для них являлся символом разрушения и изоляции. Древние греки и римляне относились к волку как к солнечному богу Аполлону, особенно в связи с мифом о волчице, которая спасла двух близнецов Ромула и Рема, будущих основателей Рима. Иногда волки ассоциировались с колдовством в северноевропейской и индейской культуре. Так, например, в скандинавской мифологии ведьма Хиндла и великанша Хиррокин ездят верхом на волке. У индейцев существовало поверье, что контакт с волками мог вызвать умственную болезнь и смерть. Согласно персидской мифологии волки являются творением злого 
духа - демона Ахримана и считаются самыми жестокими животными. Индейцы пони воспринимали волка вместе с зерном и бизоном; “рождение" и “смерть” Волка - Звезды (Сириус) было для них отражением прихода и ухода Волка по тропе Млечного Пути известного как Дорога Волка [3, с.1-4]. По мнению Н.А.Николаевой и В.А.Сафронова, неизвестно, какой образ волка (добрый или злой) возник раньше, первоначально. В своей книге они подробно рассматривают эволюцию и этапы становления и восприятия волка народами всего мира в качестве божества. Волк был тотемом уже у праевразийцев, так как у всех евразийских народов есть мифы о волке - родоначальнике; есть волчьи обереги от болезней. По евразийским поверьям это животное связывается с деторождением и приплодом скота и это - факт придания божественных функций тотему - Волку. Индоевропейская мифология свидетельствует, что в эпоху праиндоевропейского единства уже существовал культ бога - Волка, Волчьего пастыря. Волчий пастырь выступает то в человеческом обличье, то в облике волка белого, серого или сивого цвета. Белый цвет- символ светозарности, божественности происхождения. Н.А. Николаева и В.А. Сафронов рассматривают в своей книге этимологию слова “сивый”, которая восходит к праиндоевропейскому корнеслову *t'ieu(s), являющимся общим названием “бога" и “бога Солнца" IV - V тыс. до н.э., (в частности, хеттское слово sius означает "бог" и “бог Солнца"), который восходит к общеиндоевропейскому корню *t'ei - “сиять”. Поэтому слово" сивый” может означать и бога Солнца, и просто бога, а также может переводиться как “сияющий, светозарный, божественный”. Употребление таких эпитетов с Волком в казахском, русском и хакасском эпосе свидетельствует об его связи с наивысшим божественным началом, связанным со светом, солнцем. Сивые и белые волки - волшебники встречаются и в тюркских героических сказаниях. Удивительное сходство обнаруживается в вере тюркских и индоевропейских народов в волчьи обереги и амулеты, которые имеют лечебную силу. Детальное совпадение мифов о воспитательной способности волков позволяет авторам утверждать, что они восходят к общеевразийскому мифу, когда евразийцы были единым народом. В одних мифах волчицы воспитали будущих родоначальников народа, в других - героев - богатырей. Оборотничество превращение человека в волка и наоборот, вероятно, оформляло в представлениях людей зооморфно - антропоморфные переходы бога Волка. Миф о волке - оборотне, о волкодлаках относится к эпохе зарождения культа волка, к эпохе евразийского единства IX тыс. до н.э., когда волка считали тотемом, обожествляя его как неоценимого помощника на охоте на северных оленей, а позже почитая его как бога изобилия, плодовитости животных и людей. Известно, что с каждым богом связаны определенные животные, которые на поздней стадии выступают как их символ. Индоевропейские боги в конце концов приняли антропоморфное обличье (боги Древней Греции), но египетские боги так и остались наполовину зооморфными. Практически все боги ведут происхождение от зооморфных тотемов. До сих пор существует почтительно-уважительное отношение ко всем Волчьим богам у всех индоевропейских и тюркских народов (например, обязательно похоронить мертвого волка)[4, с.97115]. Согласно мифическим и фольклорным поверьям человек мог превратиться в волка в результате укуса другим человеком - волком или под воздействием проклятия. Некоторые ученые отмечают, что оборотничество было связано не только с дьяволом, но оно также могло быть следствием Божиего наказания. Так, например, тот, кого отлучали от Римской Католической Церкви, становился человеком - волком, т.е. приобщался к дьяволу. В качестве наказания христианский святой Патрик превратил уэльского короля Веретикуса в волка. Поверья об оборотнях, связанные с колдовством и болезнью ликантропии, были широко распространены в фольклоре и мифологии у многих народов мира [5, с.1,5].С принятием христианства значительно изменилось отношение человека к бывшему языческому божеству Волку - в сторону негативизма. Библия содержит 13 ссылок на волков в качестве символов кровожадности и разрушительности, а Коран - 3 ссылки, (в частности, в Суре Юсуф). Волк неоднократно упоминается в Писании как враг стада Божиего - метафора на злых людей с их стремлением к власти и бесчестной наживе так же, как и метафора на Сатану, охотящегося на невинных Богобоязненных христиан. Римская католическая Церковь часто использовала негативный образ волков для создания реальной атмосферы демонов, которые рыщут в реальном мире. Некоторое противоречие в отношении Волка наблюдается в Ветхом Завете (в Левите и Второзаконии) «волки являются либо посланниками Бога для наказания грешников, либо посланниками Дьявола по Божиему благословению для преследования истинно верующих для испытания их веры». Синкретизм языческих и христианских элементов сохранился не только в древних манускриптах, но и в археологических памятниках. Например, на Торвалдском Кресте на острове Мэн изображен бородатый человек - языческий бог Один с 
вороном или орлом на плече, пожираемый волком Фенриром в Рагнареке, в то время как на обратной стороне камня изображен Христос, одерживающий победу над Сатаной. А на Госфортском Кресте середины XI века, находящегося в Камбрии (Англия) изображено сочетание сцен из христианского Страшного Суда и языческого Рагнарека (сын Одина Видар, сражающийся с Фенриром). Вероятнее всего, подобный синкретизм символизирует победу христианства над язычеством [6, с.6], хотя христианство по своей сути и происхождению является таким же язычеством, только более усовершенствованным. Тема «хищники битвы» весьма популярна в германской поэзии. Это поэтический троп в древнеанглийской и древнескандинавской литературе, который включает волка, ворона и орла, сопровождающих любое сражение и воинов для празднования над телами убитых. Впервые этот термин был введен Ф.Магуном в 1955 г.[7, с.5]. Среди традиционных животных этого мотива самым жестоким и страшным является волк, который олицетворяет убийства и смерть. Например, в поэме «Битва в Мальдоне» поэт отождествляет викингов с волком, называя их «убийство-волки» (waelwulfas), а в поэме «Исход» египтяне описаны как «меч-волки» (heorowulfas) по мнению С.Уорда [8, с.4-6]. Хотя волк имеет сильные ассоциации с разрушением и мертвечиной, физически он описывается как «серый зверь» только в двух источниках- «Битва в Брунанбурге» и «Битва в Финнсбурге», а также как «худой» в поэме «Юдифь». Также необходимо упомянуть статью А. Джоргенсена о шумах во время сражения в древнеанглийской поэзии, которая отмечает, что «наиболее часто появляющимися шумами... являются ношение оружия и индикаторы о ментальном состоянии воинов и хищников битвы...Шум не столько сильно связан с насилием, сколько с психологическими условиями: хищники битвы это образы кровожадности. Описание этих хищников перед сражением и фокусирование на ожидании - это отличительные черты древнеанглийской поэзии, в которой чаще всего они являются пожирателями убитых, а не вестниками войны, как в древнеуэльской и древнескандинавской поэзии. Существует большая ирония в описании воя хищников как мелодичного или звонкого...Этот аспект символизма особенно заметен в поэме «Елена», в которой волк не только поет (fyrdleoth agol «пел песню войны», 27), но также представлен как привилегированный интерпретатор сражений. Волк способен прочитать знаки и раскрыть их значения другим (waelrune ne math «не скрыл руны об убийстве», 28) [9, с.322-323], т.е. обладает магическими способностями. Исходя из вышесказанного, можно предположить, что волк в англосаксонской культуре не только является хищником битвы, но и может быть рассмотрен в качестве полубожества, которое имеет значительную силу и власть над людьми. Мы согласны с мнением Д. Харпера, который считает, что «англосаксы, как и многие древнеевропейские народы имели двойное восприятие волков. С одной стороны, их боялись и ненавидели. Столетиями волков всегда выгоняли с фермерских земель» [1, ibidem, с.1]. Знаменитый проповедник - богослов древнеанглийского средневековья X века, архиепископ из Йорка Вульфстан называет дьявола werewulf (древнеангл. wer(e) «человек, мужчина» и wulf «волк»), т.е. человек - волк или оборотень - ликантроп (древнегреч. lykos «волк» и anthropos «человек»). Древнеанглийское слово were - wulf имеет два случая написания: werwulf - это имя священника, известного королю Альфреду и were - wulf - из проповеди Вульфстана. В IX веке - это имя собственное, а в XI веке - это синоним слова дьявол (wodfreca werewolf «свирепый человек - волк», от которого всем пастухам следует охранять свое стадо). Точка зрения М. Герстейн о том, что германское слово warg означает «человек - волк» была отвергнута большинством исследователей. Древнеанглийское слово wearg и warg имеют похожий корень, который, возможно, означал «удушитель», но некоторые этимологи (Т.А. Карстон и др.) видят в нем слово - табу на слово «волк», хотя это мнение не было повсеместно принято. М. Джэкоби и Д. Витенберг отмечают это, главным образом, в отношении скандинавского языка: vargr (родственное с warg ) требует значение «волк» наряду со значением «преступник, изгой» [цит по: 1, ibidem: c.1-2]. Мы не согласны с мнением И.Ф.Янушкевич, которая в своей работе называет волка священным животным бога Водена, что весьма спорно. Она пишет, что в древнеанглийской поэме "Скиталец" животные (волк и ворон) «выступают в роли проводников в иной мир без четкой его локализации» $[10$, с.120]. На наш взгляд, согласно концепции о праиндоевропейском Волчьем боге, Волк намного старше языческого бога Водена и других божеств англосаксонского пантеона, о чем свидетельствует пример дерева с волчьей головой. Остановимся на одном словосочетании, которое значительно повлияло на концептуально - семантическую структуру слова wulf - это wulfheafod - treow , буквально («волчья голова дерево») - «крест». Однако подобное значение сопровождается вопросительным знаком, т.е. Босворт и Толлер не уверены в своей трактовке этого значения. Для сравнения они ссылаются на 
древнесаксонское сложносоставное слово warag treo «крест», а также англосаксонское wearg treow «проклятое дерево, виселица, крест» [11, с. 1280]. Зафиксированы только два случая данного словоупотребления среди всех древнеанглийских памятников в вышеупомянутом Англосаксонском словаре, один из которых нам, к сожалению, не удалось найти в указанном Босвортом и Толлером сборнике древнеанглийской поэзии "Codex Exoniensis". Ealle naman habbath anne, wulfheafed - treo (Exon.Th. 437, 23) «Все имена имеют одно единственное (имя) - волчья голова - дерево». Второй случай встречается в Загадке 55: в ней говорится о чудесном дереве и кресте и о том, что все деревья имеют одно имя - дерево волчья голова и что для Бога они все полезны. Naman habbath anne, wulfheafedtreo, thaet oft waepen abaed his mondryhtne (R. 10) «Имена имеют одно (имя), волчья голова - дерево, которое часто просило оружие своего господина». Возможно, в данном контексте речь идет о распятии Христа, так как нередко загадки составлялись священнослужителями. В глоссарии “Англосаксонского читателя" словосочетание wulfheafodtreo эквивалентно словосочетанию weargtreo, т.е. «виселица в форме креста» [12, c.84]. На наш взгляд, это единственный пример наглядного изображения деревянного идола с волчьей головой и обязательного поклонения ему. Мы считаем, что это, конечно же, не крест и не виселица, а реликтовый случай, сохранившийся в древнеанглийской письменности, абсолютно точно подтверждающий исходный постулат конщепции о существовании единого праиндоевропейского Волчьего бога, которому также поклонялись и язычнФФФфики англосаксы. Нижеследующий пример подтверждает измененную функцию бога Волка: он - не священное животное, а он хозяин подземного царства мертвых, т.е. ада. Именно он, а не птица разделил человека со смертью (отдал смерти): Sumne fugel othbaer ofer heanne holm, sumne se hara wulf deathe gedaelde, sumne dreorighleor in eorthscraefe eorl gehydde,, (Wan. 980/85) «Кого-то птица унесла над глубоким морем, кого-то серый волк разделил со смертью, кого-то с окровавленным лицом в земляной могиле человек спрятал». В данном фрагменте поэмы “Скиталец” речь идет о воинах, погибших на поле битвы и есть точное указание на то, что Волк есть хтоническое существо, властелин подземного мира, а именно - всех воинов похоронят в земле. Здесь также концептуальный образ Волка - его предполагаемый архетип "Волчий бог” воспринимается весьма двусмысленно и размыто. По характеру поэма написана в христианском русле: речь идет о Сыне (Христе), Небесном Отце
- Боге, - пребывающих в величии славы. Поэтому на христианском фоне серый волк ассоциируется прежде всего с опасным хищным зверем, который может убить человека, отделить его смертью от жизни. Следует отметить, что в поздних прозаических произведениях также сохраняется некоторое противоречие, (например, древнеанглийский “Лечебник”). С одной стороны, к Волку относятся как к простому животному, ничем не выделяя его среди других зверей, а с другой стороны, подчеркивается его целебная сила, его защитные свойства для оказания помощи людям (в заговорах, амулетах, заклинаниях). В предисловии О. Кокейна к "Лечебнику" говорится о книге Апулиуса “Травник” (Гербарий). На переднем плане обложки книги изображены змеи, а на заднем фоне - много разных животных, среди которых есть и волк. В этом же предисловии Альберт Великий пишет в своем трактате "О достоинствах трав“: «Если собрать молодую траву в августе и завернуть ее в лавровый лист вместе с волчьим зубом, никто не сможет произнести дурного слова тому, кто будет это носить. Если положить это под подушку, то во сне человек, у которого украли, увидит вора и все украденные вещи» [13, xii, xxxiv]. В этом же “Лечебнике" встречается употребление умлаутированной словоформы (u - y) wylfen(n) «волчица»: Gif beo drinceth wylfene meolc $(362,13)$. «Если пчела пьет молоко волчицы».... Следует отметить, что лексемы wylf и wylfen(n) «волчица» весьма редко употребляются по сравнению со словом wulf, поэтому концептуальный дуализм и синкретизм в них слабо выражен. В Англосаксонском словаре Босворта - Толлера, кроме прямого значения «волчица», зафиксировано еще его переносное значение с отрицательной коннотацией - Bellona, т.е. «ярость, бешенство, богиня войны, мать Mapca, бога войны» [11, с.1285], но только в текстах на латинском языке. В своей статье Д. Харпер считает, что «волк долгое время ассоциировался с определенным антисоциальным поведением людей. Поэтому неудивительно, что wer(e)wulf “человек - волк" и гнусный преступник ассоциативно связаны. Романский взгляд на волка отражен в лат. lupa буквально "волчица" - термин, которым называли проститутку». Харпер объясняет взаимосвязь между древнегреческими богами и волками тем, что могли смешиваться и неправильно употребляться древнегреческие слова lykos “волк” и lyke “свет”. Согласно А.Б. Куки “Зевс: изучение древней религии" Зевс Lykaios был Зевсом волком - богом и также Зевсом - богом Света, т.е. Светлым богом. В Аркадии волков держали в храме - святилище Зевса Lykaios как священных животных. Им в жертву приносили людей. Много образов из 
этого храма было одето в волчьи шкуры “ [цит. по: 1, ibidem: c.3]. В этой связи следует отметить, что «юноши в англосаксонском обществе языческого периода проходили магическо религиозные испытания, в процессе которых их нередко доводили до "боевого бешенства" с помощью наркотических средств. По мнению польского этнографа А.Гейштора, надевание шкуры хищника должно было изменять их психику, освобождая от человеческих норм поведения». Распространенные верования в волков - оборотней, очевидно, как раз связаны с данным обрядом. Охотники - воины должны были регулировать свое поведение исходя из того, что они есть воплощение зверя - тотема. По словам В.Ю. Михайлина, во время “очистительных" магических обрядов бывшие “волки” претерпевали весьма болезненные испытания, заливая кровью жертвенник Афродиты» [цит. по: 10, с. 124 -125] .

\section{References:}

1. Harper D (2011) Wolf and Werewolf. Available:

http://www.collasius.org/LITERATUR/04HTML/wolf-werewolf.htm (Accessed: 9.07.2011).

2. Lebedev VY, Viktorov VY (2011) Religiovedenie. Moscow: «Yurayt», 2011.-492 p.

3. (2011) Wolves in folklore, religion and mythology.

Available: http://en.wikipedia.org/wiki/Wolves\%20in\%20f olklore, \%20religion\%20and\%20mythology (Accessed: 25.05.2011).

4. Nikolaeva NA, Safronov VA (1999) Istoki slavyanskoy i evraziyskoy mifologii. Moscow: «Belyy volk» Kraft Gup Oblizdat, 1999.-310 p.

5. (2011) Werewolf. Available: http://en.wikipedia.org/wiki/Werewolf (Accessed: 25.05.2011).

6. (2011) Fenrir. httn://en wikipedia org/wiki/Fenris Available: 25.05.2011).
7. Magoun FP (2015) The theme of the beasts of battle in anglo-saxon poetry. Neuphilologische Mitteilungen 56.

8. Ward C (2015) The beasts of battle : wolf, eagle and raven in Germanic poetry. Available: http://www.vikinganswerlady.com/beasts.shtml (Accessed: 10.11.2015).

9. Jorgensen A (2015) The trumpet and the wolf: noises of battle in Old English poetry. Available:

http://www.google.ru/search?sourceid=navclien t\&hl=ru\&ie=UTF (Accessed: 10.11.2015).

10. Yanushkevich IF (2009) Lingvosemiotika anglosaksonskoy kul'tury. Volgograd, 2009.$500 \mathrm{p}$.

11. Bosworth J, Toller TN (1991) An Anglo Saxon Dictionary. New York, 1991.-1302.

12. (2011) An Anglo-Saxon Reader. Available: http://www.archive.org/stream/anglosaxonreade rOOmarcuoft (Accessed: 10.04.2011).

13. Cockayne O (1865) Leechdoms, Wortcunning and Starcraft of Early England. Vol. ii. London, 1865. 